\title{
One Attempt to Create a Digital Library from Scratch
}

John Dewees, MLIS

Supervisor Digitization Services, Toledo Lucas County Public Library

\section{tlcpl.org/anwo}

\section{Project Background}

When approaching any endeavor it is a pretty common practice to lean into existing strengths, so when starting a new position in a new library, I set out to do this with my intrepid team members at the Local History and Genealogy department of the Toledo Lucas County Public Library (TLCPL). Our Special Collections Librarian, Ed Hill, had been championing a particular (and massive) subset of our archival collections: architectural drawings and documentation. Over the years TLCPL has accessioned drawings, photographs and supporting documentation, and it has been Ed's goal to successfully leverage these materials in whatever way possible. As the new digitization librarian, I worked with him to develop a means whereby the collection can continue to be processed, organized and ultimately end up online.

The scope of these architectural collections is extensive: thousands of photographs, tens of thousands of sheets of architectural drawings, and hundreds of thousands of pages of supporting documentation. With few exceptions, these materials have been donated to the library; in some cases a donation may be a single commission for a house, and in others the collections have come in as corporate archives donated wholesale, the largest of which has been the Bauer, Stark, and Lashbrook Collection that came to the library over a series of accessions and over a number of years. All the architectural collections are either the work of Toledo-area architects or commissions depicting Toledo-area buildings. While the Bauer, Stark, and Lashbrook Collection is the single largest, and accounting for over 120 years of history, other prominent Toledo architects are also featured in the collection including Carl C. Britsch, Alfred A. Hahn, George B. Rheinfrank, Harry W. Wachter, and David L. Stine, who operated individually or as part of a larger firm over the course of their careers. The comprehensiveness of each firm's collection varies considerably.

Due to the scope of the Bauer, Stark, and Lashbrook Collection in particular, in-depth processing has as of yet not been possible, and inventories in the form of spreadsheets have been created for the various architects and firms to collect metadata about the individual commissions. A first effort in continuing to process this collection has been to consolidate all of the inventories into a single union list, to allow reference librarians to more easily determine if we can assist patrons in their queries about specific addresses and to ensure that all collections are being described consistently. Currently the bulk of the architectural collections are housed in off-site storage and are retrieved monthly in response to library or patron needs. As materials are pulled, their contents are double-checked against the union 
inventory to ensure accuracy, and boxes that contain unidentified materials are researched and added to the inventory.

This workflow of pulling materials provides an excellent opportunity to digitize them, and in nearly all cases a portion of every commission is digitized and added to our repository, even if only an exterior elevation or floor plan. The drawings themselves are prioritized, and the supporting documentation, such as construction parameters, contracts, invoices, etc., are rarely digitized and only if it is of high interest. To supplement the architectural drawings, contemporary photographs are taken of the building (if extant) by library staff and included in the digital version of the commission in the repository.

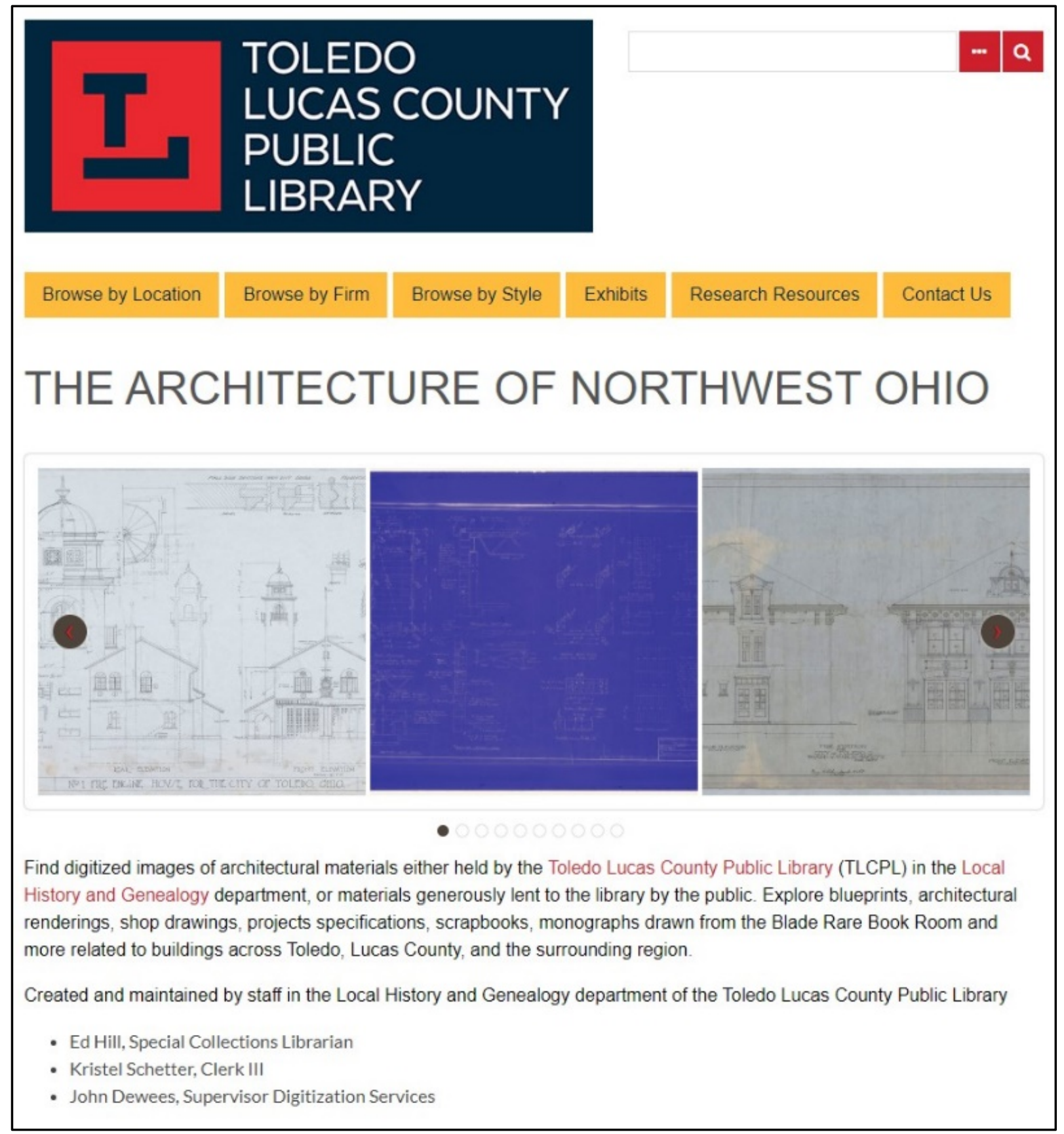

Architecture of Northwest Ohio Landing Page 


\section{Providing Access}

The digital library has two primary platforms that are used to power this resource. The access solution is built in Omeka, entitled "The Architecture of Northwest Ohio" (ANWO), that creates an interface custom built to navigate the commissions, while adding additional data. The repository solution is CONTENTdm, through Ohio's state-wide digital library Ohio Memory, which acts as storage for the digital surrogates and the complete metadata record for individual commissions. Representative images from a commission are uploaded to Omeka, with links back to the full record in CONTENTdm. Creating the interface in Omeka was a highly iterative process as different aspects of this project have progressed at different rates and continues to change over time; creating an interface that scaled well continues to provide an interesting challenge.

For instance, books on architecture drawn from our rare book collection are scanned as a supplementary resource to the exhibit. In mid 2019, there was only a handful of digitized monographs, and they could easily be displayed on the homepage for the exhibit, however as other resources such as scrapbooks and manuscript material have been digitized, all these resources have been broken off into their own area as a supplementary reference library to the core collection.

Creating ANWO has allowed us to contextualize the collection in a way that is challenging in a repository environment, as well as enrich the collection with additional data to aid researchers. Creating the union inventory of architectural commissions was the first step in providing more control of the collection. This inventory includes information on what architect or firm created the commission, who requested the project and how large the commission is, the location of the building and other assorted information. A secondary project has been to create a comprehensive list of architects and firms working in Toledo from the late $19^{\text {th }}$ century to the present by transcribing entries in city directories into a spreadsheet, and this has been an indispensable resource for creating useful supplemental data. When an architect or firm is added to ANWO for the first time, this Toledo architects list is consulted, and an account of exactly how long the architect worked in Toledo is created, along with information on what firms they were part of. 


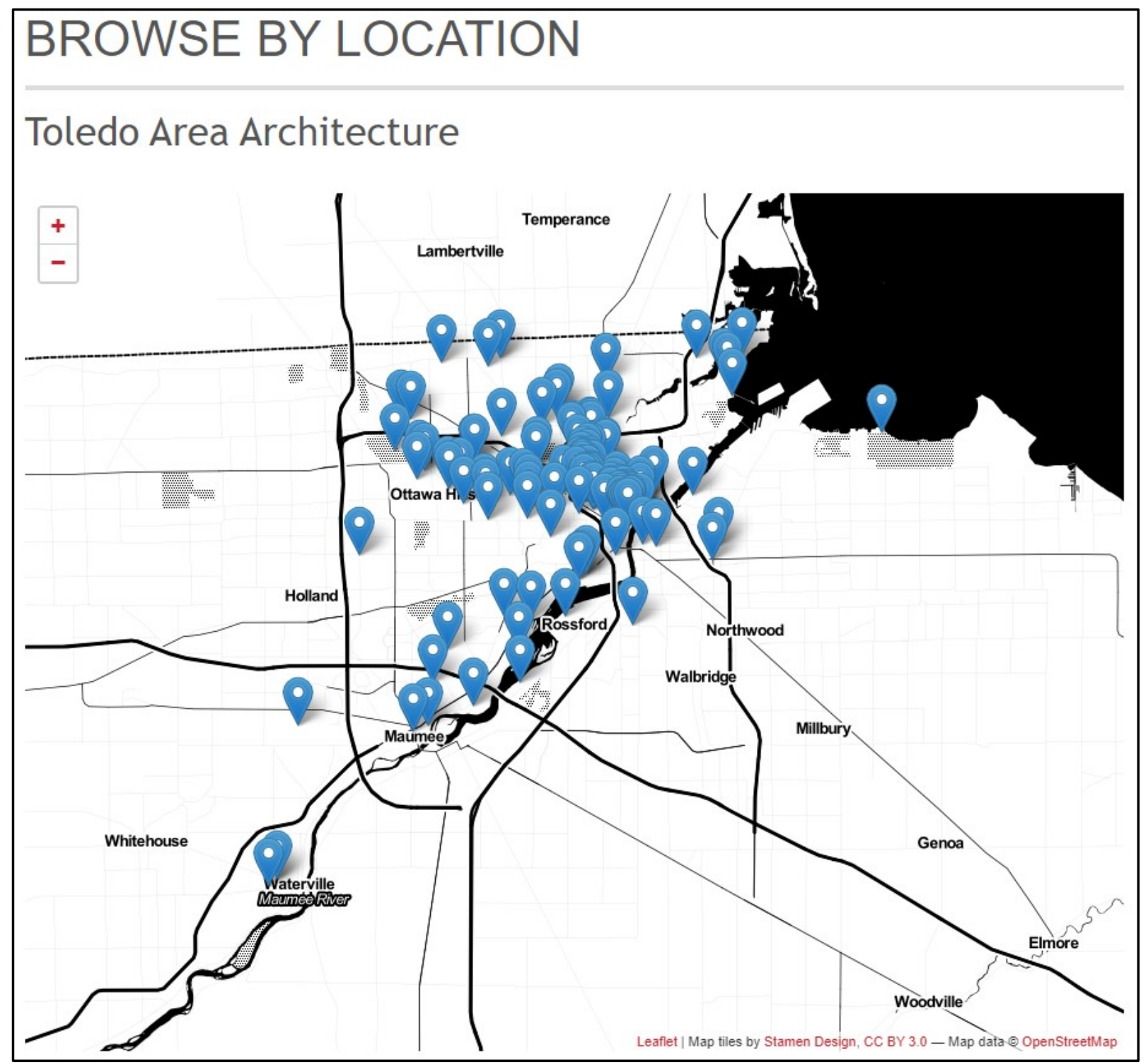

Architecture of Northwest Ohio - Browse by Location

ANWO provides three primary means of interrogating the content: geospatially, by the designing architect/firm, and by the style of the building. If a patron is only looking for an address, a straightforward search in Ohio Memory will turn up that information. However, if a patron is looking to investigate what we have in a neighborhood, easily wants information on a specific firm, or all the Colonial Revival buildings in the area, the repository can provide this information, but in a far less user-friendly fashion. The Geolocation plugin for Omeka is an easy and highly customizable means to create an excellent geospatial interface and visualization for our collections, and we have two maps currently, one for Toledo/Lucas County, and one for the larger region currently incorporating Ohio and Michigan. To explore the work of individual firms, we first create pages for cities and then populate each of these pages with the firms that were based there. Each firm's page then has list of all digitized commissions we have for them. In the future we hope to further enrich these firm's pages with additional information to create a more robust history of their work. 
This interface also makes our digital collection development easier, as we want to create a highly diverse set of architectural collections. To do this we look to digitize architectural drawings of buildings in neighborhoods of underrepresented communities, those from underrepresented backgrounds in the field of architecture, geographically diverse buildings around all corners of the county, diverse styles and purposes of buildings, and by scanning from different time periods.

A larger initiative at the Toledo Lucas County Public Library is to create published open data sets. On a monthly basis, all metadata from CONTENTdm is downloaded as standard Dublin Core XML and uploaded to a publicly available Dropbox folder that is accessible through GitHub and licensed under a GNU General Public License. While the architectural collections metadata is only one sub-set of the larger mass of data, this allows it to be freely provided to the public for mining and use in GIS or digital humanities projects. Where possible we also enrich this metadata with GPS coordinates and ISO 8601 date fields to make the material as accessible as possible.

Next Steps

Development of this project is ongoing and a number of future enhancements are planned. Ideally the union inventory of architectural materials will be exposed to the public through the library website and provide the basis for a dataset that can be searched and combined with a webform that will allow a simple and straightforward means of requesting drawings in our collection that can be easily delivered through Dropbox. This massive dataset could also be combined with existing open data initiatives and distributed in a coded and machine-readable format.

The architectural collections do not exist in isolation from our other digitized materials and integrating these resources together has been a recent goal. A custom federated search engine that leverages the CONTETNdm and Internet Archive APIs, combined with a custom solution for our digital exhibits in Omeka, has been implemented that allows all our digitized resources to be searched together. As all our digitized resources reside in Ohio Memory, among dozens of other collections from other libraries, archives, and museums, this provides a means of isolating our content for search and combining it with our other access solutions. Thus, when searching an address, you will see any instances in our primary CONTENTdm collection (which includes our digitized architectural materials, as well as the bulk of our photo collections), as well as any instances it appears in our collection of county auditor's images, our newspapers collection, or our community driven photo collection. In the same spirit of implementing new means for researchers to interact with our digital materials, another project has been to develop a geospatial map interface for all our digitized collections (not just architecture), allowing any record with GPS coordinates to be mapped and browsed. This 
allows researchers to see the full scope of our collections on a map, surfacing disparate resources that happen to have geographic proximity.

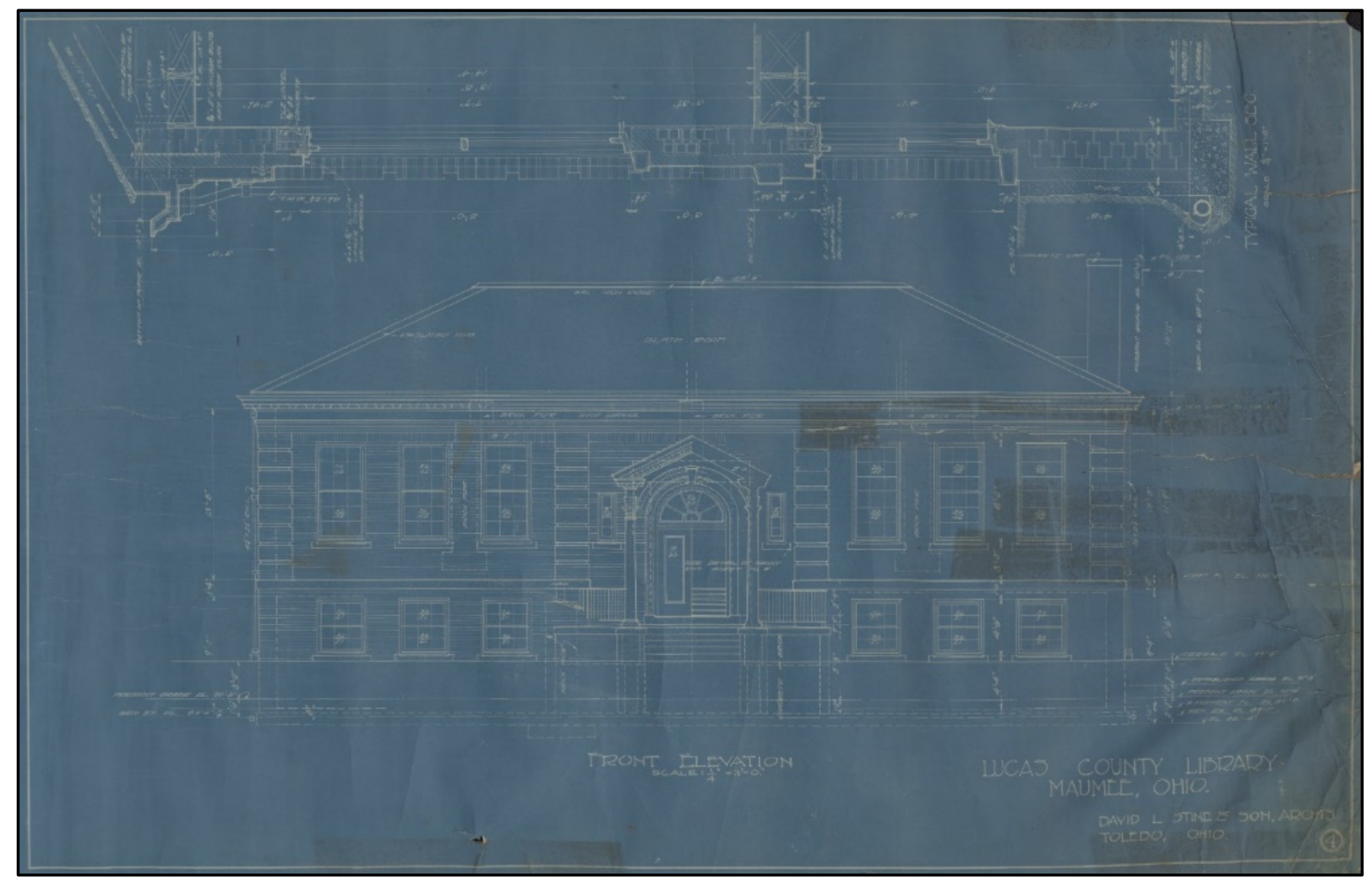

Maumee Library exterior elevation, 1916

A blank slate project like this can be truly exhilarating as there is no shortage of directions that can be taken. ANWO changes and progresses significantly on a month to month basis and I look forward to seeing where it will take me in the future as we craft more robust versions of it in the future.

\section{Acknowledgements}

I'd like to thank the dedication and teamwork of Ed Hill (Special Collections Librarian, and curator for architectural collections), Kristel Schetter (Clerk III, who is instrumental in processing, describing, and digitizing materials), Andy Lechlak (Digital Strategist, who is responsible for creating the federated search and geospatial search tools), as well as Gayle Martinez and Christina Gaydos (Supervisor Cataloging Services and Cataloger respectively, who are essential to enriching and proofing our metadata). Their tireless work has been absolutely key to the continued realization of this project.

Inset: Enriching the Digital Library

One advantage to using a tool like Omeka as an access layer for a repository like CONTENTdm is that you can take certain slices of content from the repository that are useful in the given digital library without wading through irrelevant content. One example of this is the "Research 
Resources" page of ANWO where non-core materials are presented for continued research in addition to the architectural commissions. Thus far we've added:

- A list of how the different architectural firms described have changed over time, gaining and losing named partners, or acting as solitary actors

- Links to digitized scrapbooks and vertical files of newspaper clippings on Toledo buildings and architects

- Scrapbooks loaned to us from the Toledo Firefighters Museum that document the history of the firehouses in the city

- Monographs from our rare book collection

- Select manuscript material detailing the sale of land and assets for a significant Toledo manufacturer

- A key taken from a commission providing information on typical symbols used in architecture and engineering drawings in 1921

- Links to photograph collections in our digital holdings with extensive architectural images

- Resources from outside our library such as links to historic district commission websites, Sanborn Fire Insurance maps from the Ohio Web Library, and books digitized by institutions like the State Library of Ohio 